\section{Mortality Associated With Enterococcal Bacteremia}

Caballero-Granado and coinvestigators from Cadiz, Spain, conducted a prospective, matched case-control study to analyze the attributable prognosis of enterococcal bacteremia (assessed by its attributable mortality rate and duration of hospital stay). All adults with an episode of enterococcal bacteremia without endocarditis were included. A control patient was randomly selected for every case-patient and matched by gender, age, and hospital ward. Univariate and multivariate analyses were performed. A total of 122 pairs were included, and incidence of enterococcal bacteremia was 2.3 episodes per 1,000 discharges. Crude 30-day mortality rates for case- patients and control-patients were $23 \%$ and $17 \%$, respectively $(P=.29)$; thus, the estimated attributable mortality rate was $6 \%\left(\mathrm{CI}_{95},-4 \%-16 \%\right)$. The mean duration of hospital stay of case-patients and control-patients was 38 and 17 days, respectively $(P<.001)$; thus, the estimated attributable duration of hospital stay was 21 days $\left(\mathrm{CI}_{95}, 7-32\right.$ days).

The authors concluded that enterococcal bacteremia without endocarditis does not increase risk of death by itself but extends the duration of hospital stay of patients who develop it.

FROM: Caballero-Granado FJ, Becerril B, Cuberos L, Bernabeu M, Cisneros JM, Pachon J. Attributable mortality rate and duration of hospital stay associated with enterococcal bacteremia. Clin Infect Dis 2001;32:587-594.

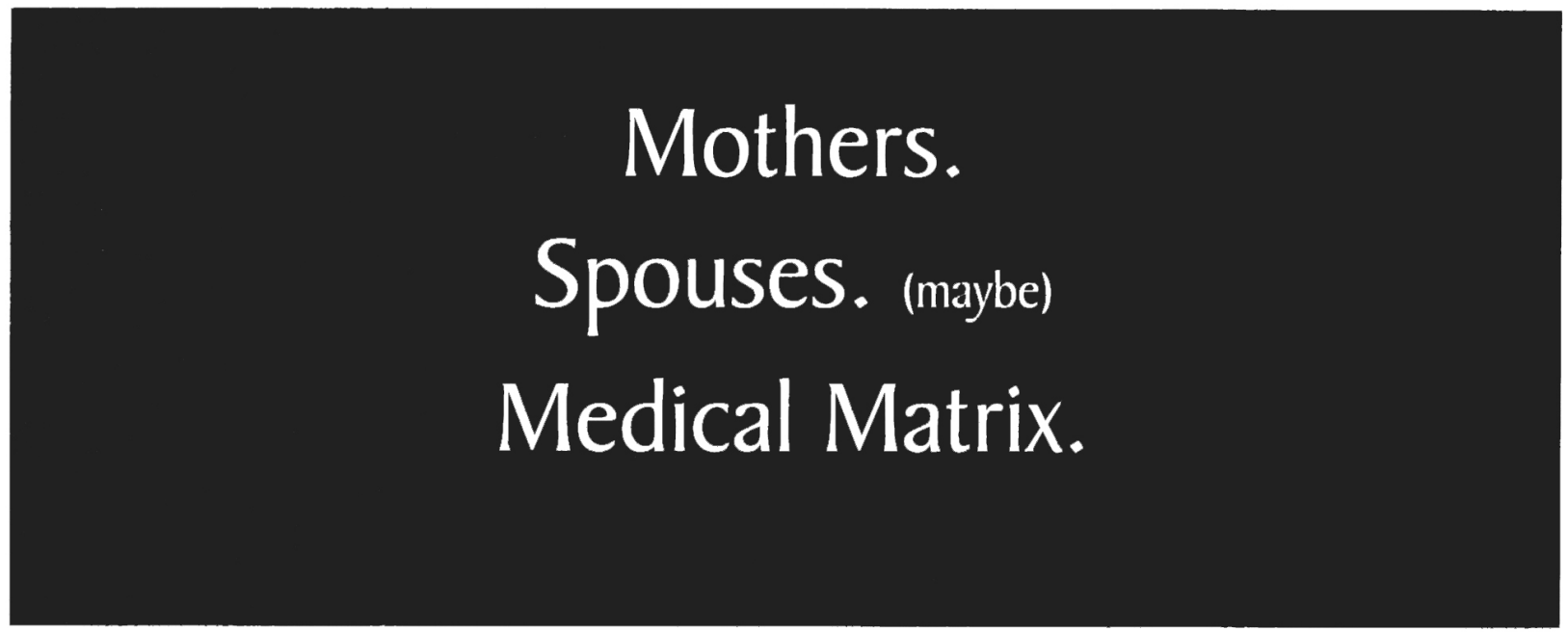

What do they have in common? You place your trust in them. When searching the Internet for credible medical information, you need a resource you can trust. The Lancet quotes that "Medical Matrix is the most comprehensive compendium of reliable medical information on the Internet."

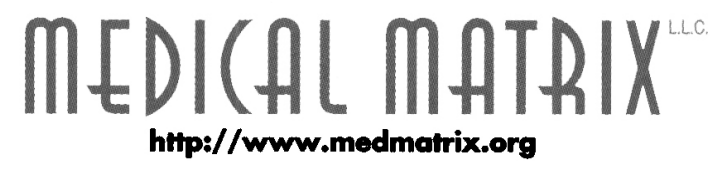

The largest, peer-reviewed directory to the medical Internet.

Free registration. 